\title{
Comparison of three models to estimate the slant path atmospheric attenuation in central receiver solar thermal plants under Indian climatic conditions
}

\author{
Bhrigu Rishi Mishra ${ }^{a}$, Natalie Hanrieder ${ }^{\mathrm{b}}$, Anish Modi ${ }^{\mathrm{a}, *}$, Shireesh B. Kedare ${ }^{\mathrm{a}}$ \\ ${ }^{a}$ Department of Energy Science and Engineering, Indian Institute of Technology Bombay, Powai, Mumbai 400076, Maharashtra, India \\ ${ }^{\mathrm{b}}$ German Aerospace Center (DLR), Institute of Solar Research, Plataforma Solar de Almería (PSA), Ctra. de Senés $\mathrm{s} / \mathrm{n} \mathrm{km} 4$, Apartado 39, 04200 Tabernas, Spain
}

\section{A R T I C L E I N F O}

\section{Keywords:}

Central receiver solar thermal plant

Aerosol optical depth (AOD)

AERONET

REST2

MODIS

\begin{abstract}
A B S T R A C T
This paper compares three attenuation models for the distinct meteorological conditions of India and assesses the feasibility of using the satellite data to calculate the slant path extinction coefficient and the slant path transmissivity of the lower atmosphere. The attenuation models are compared for the sites of Pune, Kanpur, and Jaipur. The AERONET data is used with REST2 to model the direct normal irradiance and the total optical depth. The results indicate that the three models give similar transmissivity values for low aerosol concentrations. As the aerosol concentrations increase, the difference in the slant path transmissivity as calculated by two of the models increases with respect to the third reference model.

The slant path transmissivity comparison shows that for AERONET AOD at $550 \mathrm{~nm}$ (AOD550) less than 0.3 , the relative error in the transmissivity values estimated by two of the compared models with respect to the third model is not higher than $10 \%$ for Pune, $18 \%$ for Kanpur, and $12 \%$ for Jaipur. The mean relative error in the slant path transmissivity values obtained from the reference model using MODIS data with respect to the values obtained using AERONET data is $4.8 \%, 10.2 \%$, and $9.2 \%$ for Pune, Kanpur, and Jaipur, respectively. A difference of 0.2 between AERONET AOD550 and MODIS AOD550 values resulted in a difference of $0.05-0.08$ between the transmissivity values calculated by the reference model using AERONET AOD550 and using MODIS AOD550 for the three sites.
\end{abstract}

\section{Introduction}

In a central receiver solar thermal plant, solar radiation is reflected by the heliostats (mirrors) and concentrated on a receiver placed on the top of a tower. In its pathway, the reflected solar radiation interacts with different atmospheric components such as air, water vapour, and aerosol particles. Because of these atmospheric components, scattering and absorption of the solar radiation take place, thereby reducing its intensity. The more the distance between the heliostat and the receiver, the higher will be the attenuation.

Accurate modelling of slant path atmospheric attenuation of solar radiation in central receiver solar thermal plants is a major challenge (Hanrieder, 2016). Static models have been developed to estimate this attenuation (Vittitoe and Biggs, 1978; Leary and Hankins, 1979; Kistler, 1986; Vittitoe and Biggs, 1981). Some of the models have been modified (Belhomme et al., 2009; Buck, 2011; Ballestrìn and Marzo, 2012) and are being used in the efficiency calculation of heliostat fields. There are also attenuation models which take site-specific inputs such as aerosol optical depth (AOD), precipitable water vapour amount (Pitman and Vant-Hull, 1982; Tahboub et al., 2013; Polo et al., 2016a; Elias et al., 2016), and direct normal irradiance (DNI) at ground level (Sengupta and Wagner, 2012; Hanrieder et al., 2016). Hanrieder et al. (2017) presents a detailed summary of the various attenuation models.

The slant path attenuation of solar radiation in a central receiver solar thermal plant depends on the concentration of aerosol particles, the amount of water vapour, and the number of air molecules present between the heliostat and the receiver. Gueymard et al. (2017) and Elias et al. (2017) showed that air molecules and water vapour result only around $2 \%$ to $3 \%$ of attenuation in the solar radiation between heliostat and the receiver. Thus, most of the attenuation of solar radiation is because of the aerosol loading present in the pathway of heliostat and receiver. The attenuation models, as discussed by Hanrieder et al. (2017), may give different results for different atmospheric aerosol loading as most of the models are developed by considering site-specific inputs. Thus, it is necessary to examine the reliability of these attenuation models for different atmospheric conditions. Hanrieder et al.

\footnotetext{
* Corresponding author.

E-mail address: anishmodi@iitb.ac.in (A. Modi).
} 


\section{Nomenclature}

\section{Abbreviations}

\section{AERONET}

AOD

AOD550

DNI

MBE

MODIS

\section{MRE}

REST2

\section{Symbols}

$a, b$
$g$
$h$
$H$
$p$
$R_{s}$
$T$
$T_{r}$
$u_{n}$
$u_{o}$
$w$
$x$

\section{Greek symbols}

$$
\begin{aligned}
& \alpha \\
& \beta \\
& \lambda \\
& \tau \\
& \theta_{z}
\end{aligned}
$$

Aerosol robotic network

Aerosol optical depth

Aerosol optical depth at $550 \mathrm{~nm}$

Direct normal irradiation

Mean bias error

Moderate resolution imaging spectroradiometer

Mean relative error

Reference evaluation of solar transmittance, 2 bands

Model coefficients

Acceleration due to gravity $\left[\mathrm{m} \mathrm{s}^{-2}\right]$

Altitude [m]

Scale height of atmosphere [m]

Pressure $[\mathrm{hPa}]$

Specific gas constant $\left[\mathrm{J} \mathrm{kg}^{-1} \mathrm{~K}^{-1}\right]$

Temperature [K]

Transmissivity

Nitrogen dioxide amount [Dobson unit]

Ozone amount [Dobson unit]

Precipitable water vapour amount [mm]

Distance [m]

Ångstrom exponent
Extinction coefficient $\left[\mathrm{m}^{-1}\right]$
Wavelength $[\mathrm{nm}]$
Optical depth
Solar zenith angle $\left[^{\circ}\right]$

Subscripts

ang

Ångstrom

ext

\section{Extinction}

MODIS data. Gueymard and Yang (2020) compared MODIS retrieved AOD and reanalysis models CAMS and MEERA-2 and reported the substantial differences in AOD550 mainly because of the elimination of cloud interference.

In this study, we compare three attenuation models (Tahboub et al., 2013; Polo et al., 2016a; Hanrieder et al., 2016) for three sites in India using the AERONET data (Holben et al., 1998). These three sites have different atmospheric and geographic conditions, i.e. altitude, aerosol concentration, precipitation, and humidity. The satellite data MODIS AOD (Remer et al., 2005) is also used to calculate the slant path attenuation. The transmissivity values obtained using the ground data are compared with those obtained using the satellite data in order to evaluate the feasibility of using the satellite data for attenuation calculations in the pathway of heliostat to receiver in central receiver solar thermal plants.

The rest of the paper is structured as follows. Section 2 presents a detailed description of the compared attenuation models, the data sources, and the methodology. Section 3 presents the results and discussion from the study. Section 4 concludes the paper.

\section{Methodology}

For the comparative analysis, the sites of Pune $\left(18.5^{\circ} \mathrm{N}, 73.8^{\circ} \mathrm{E}\right.$, altitude $595 \mathrm{~m}$ ), Jaipur $\left(26.9^{\circ} \mathrm{N}, 75.8^{\circ}\right.$ E, altitude $\left.450 \mathrm{~m}\right)$, and Kanpur $\left(26.5^{\circ} \mathrm{N}, 80.2^{\circ} \mathrm{E}\right.$, altitude $\left.123 \mathrm{~m}\right)$ are considered. Pune is situated in a basin surrounded by uplands and hills. The weather is dry (Gadgil and Dhorde, 2005). Jaipur is located in the semi-desert land of Rajasthan and thus it has hot summers and cold winters (Tyagi et al., 2011). Kanpur is among the most polluted cities in India. Located in the Ganga basin, it is hot and dry in summer and cold in winter (Chakraborty and Gupta, 2009). According to the Köppen climate and classification, Pune and Jaipur are classified as type BSh, i.e. hot semi-arid climate, and Kanpur is classified as type Cwa, i.e. monsoon-influenced humid subtropical climate (Geiger, 1954). The attenuation models by Tahboub et al. (2013), Polo et al. (2016a), and Hanrieder et al. (2016) are used for comparison. For brevity, these models are referred to as model M1, model M2, and model M3, respectively, in the rest of the paper. The model by Tahboub et al. (2013) uses the ground measurement of DNI to model the attenuation. In the model by Polo et al. (2016a), five different aerosol load conditions have been selected to model the attenuation. The maximum AOD at $550 \mathrm{~nm}$ (AOD550) considered in deriving the model by Polo et al. (2016a) is 0.72 .

The models M1 by Tahboub et al. (2013) and M2 by Polo et al. (2016a) in this comparison do not consider the vertical aerosol particles distribution in the atmosphere, which plays a significant role in the modelling of the slant path atmospheric attenuation. The aerosol loading in the atmosphere changes with respect to the altitude, and so does the vertical extinction coefficient. Thus, using the average vertical extinction coefficient profile of aerosol loading in the attenuation models may not give an accurate result. López et al. (2017) showed that different vertical aerosol profiles will lead to different solar energy losses in slant path attenuation calculation. Therefore, the site dependent vertical extinction coefficient factor should also be considered in the modelling of attenuation. The model M3 by Hanrieder et al. (2016) considers the vertical distribution of aerosol loading by using two constants $a$ and $b$. Therefore, these three models (Tahboub et al., 2013; Polo et al., 2016a; Hanrieder et al., 2016) have been chosen for this study as they are derived using different approaches. This comparison enables to comment not only on the suitability of these models for different aerosol concentration regions but also on the methodology used for deriving the correlations used in these attenuation models. A study on the validation of model M3 for three different sites in Spain and Morocco is shown by Hanrieder et al. (2019). The study resulted below $5 \%$ of mean bias error with respect to a reference data set. So, we are assuming that the model M3 is the most accurate transmissivity model in the light of work done by Hanrieder et al. (2019) and hence we are considering model M3 as a reference model to compare other two models. The detailed methodology employed in this study is shown in Fig. 1. 

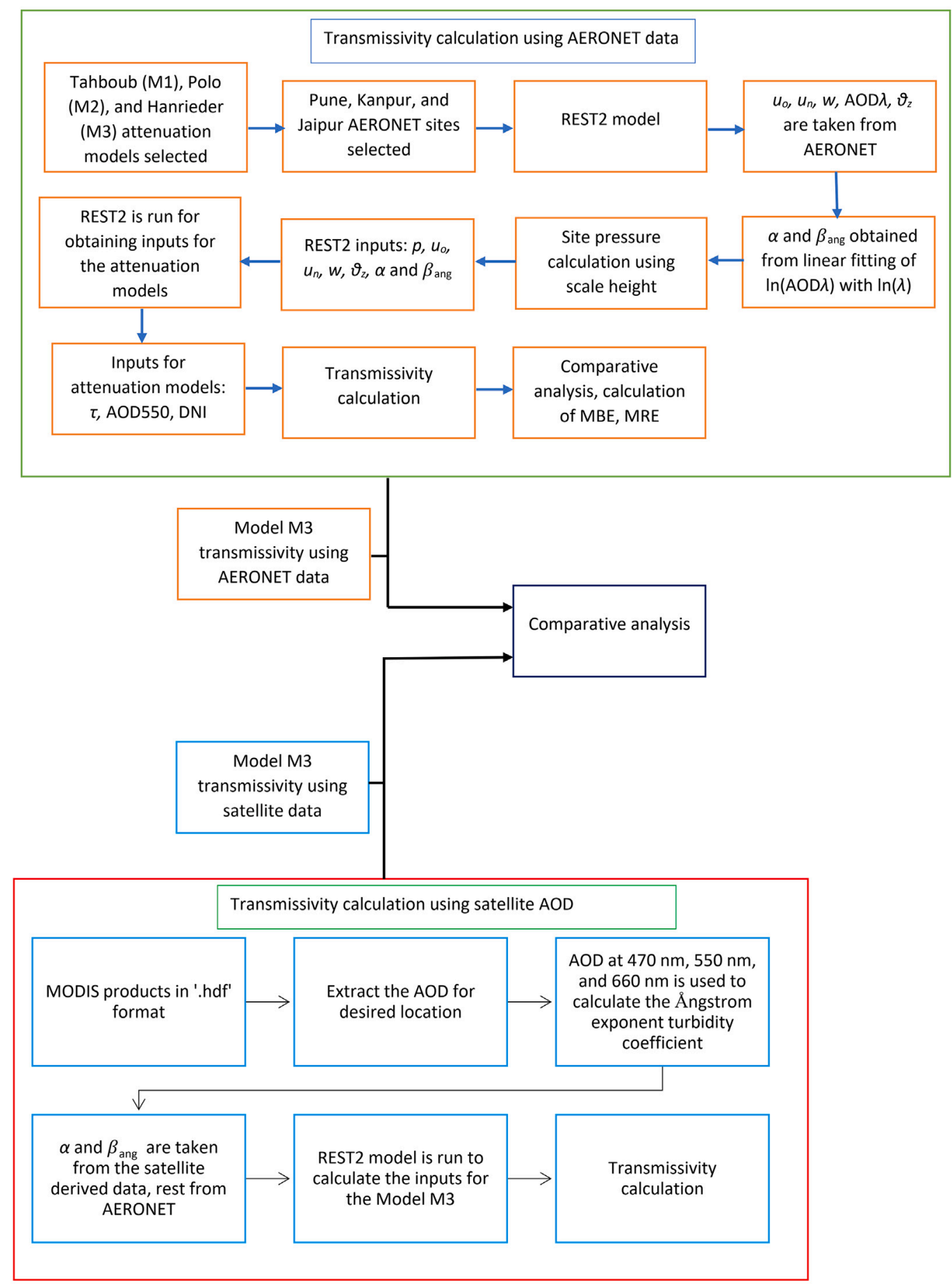

Fig. 1. Methodology of comparative analysis.

\subsection{Data sources}

The ground and satellite AOD data are taken from AERONET (Holben et al., 1998) station and MODIS, respectively, whereas for DNI, REST2 model (Gueymard, 2008) is used. These are elaborated in Sections 2.1.1 to 2.1.3.

\subsubsection{AERONET}

AERONET (AErosol RObotic NETwork) is a world-wide distributed network for measuring atmospheric aerosol properties and consists of ground-based sun photometers (Holben et al., 1998). It reports the spectral AOD at different wavelengths. However, it does not provide
AOD550, which may be calculated using the following relation (Singh et al., 2017):

$\operatorname{AOD} 550=\operatorname{AOD} 500\left(\frac{550}{500}\right)^{-\alpha}$,

where, $\alpha$ is the Angstrom exponent for wavelength range $440 \mathrm{~nm}$ to $870 \mathrm{~nm}$. If AOD500 is not available, then AOD at $675 \mathrm{~nm}$ can be considered as suggested by Singh (2018). The values for AOD550 may also be estimated using other methods, e.g. a quadratic polynomial interpolation method as suggested by Gueymard and Yang (2020). The obtained AOD550 values from the two methods (Singh et al., 2017; Gueymard and Yang, 2020) have negligible differences with an average 
difference of $2.3 \%, 1.03 \%$, and $0.88 \%$ for the considered data points for Pune, Kanpur, and Jaipur, respectively.

\subsubsection{MODIS}

Ground measured AOD is not available for all possible sites on earth. Thus, satellite data can be an alternate solution to provide the AOD values for the atmosphere. Multi-angle Imaging Spectroradiometer (MISR) and Moderate Resolution Imaging Spectroradiometer (MODIS) are the satellite platforms that provide AOD (Zhong and Kleissl, 2015). The satellite data can be used to calculate DNI at the earth surface (Polo et al., 2016b). Terra and Aqua satellites on-board a spectroradiometer, commonly known as MODIS, for measuring total vertical AOD of the atmosphere (Remer et al., 2005). Terra overpasses the equator at +5 UTC and Aqua passes equator at +8 UTC. MODIS has 36 spectral bands. The AOD data is available in $10 \mathrm{~km} \times 10 \mathrm{~km}$ and $3 \mathrm{~km} \times 3 \mathrm{~km}$ grid resolutions. In addition to AOD, MODIS also measures the precipitable water vapour amount. In this study, MODIS collection 6.1 products (Wei et al., 2019) for the year 2015 have been used. "Corrected_Optical_Depth_Land" variable of MOD04_3k (3 km $\times 3 \mathrm{~km}$ grid data) is used to obtain the AOD at $470 \mathrm{~nm}, 550 \mathrm{~nm}$, and $660 \mathrm{~nm}$.

\subsubsection{Modelled DNI data}

Because of the unavailability of the measured DNI at the three sites, it is necessary to find a different way to obtain the DNI values for the three sites. For this purpose, REST2, a solar radiation model for predicting clear-sky irradiance (Gueymard, 2008), is used to obtain the DNI values for the three sites. For DNI calculation, the model takes atmospheric inputs of pressure, water vapour amount, ozone thickness, nitrogen dioxide amount, Ångstrom exponent $\alpha$ in two wavelength regions (below $700 \mathrm{~nm}$ and above $700 \mathrm{~nm}$ ), Ångstrom turbidity coefficient $\beta_{\text {ang }}$ (AOD at $1000 \mathrm{~nm}$ ), and solar zenith angle. It is a two band model. In our study a single value of $\alpha$ is selected for both the bands. $\alpha$ and $\beta_{\text {ang }}$ are used in REST2 model to calculate the AOD:

$\operatorname{AOD} \lambda=\beta_{\text {ang }} \lambda^{-\alpha}$,

where $\operatorname{AOD} \lambda$ is the AOD at wavelength $\lambda, \beta_{\text {ang }}$ represents the amount of aerosol present in the atmosphere in the vertical direction at $1000 \mathrm{~nm}$ and $\alpha$ signifies the size distribution of the aerosol particles. A higher value of $\alpha$ implies a higher ratio of small particles to large particles. Typically, $\alpha$ varies between 0 and 4 , and $\beta_{\text {ang }}$ varies between 0.0 and 0.5 (Iqbal, 1983).

For $\alpha$ and $\beta_{\text {ang }}$, a linear fitting of logarithmic AOD and the corresponding logarithmic wavelength is done using Eq. (2):

$\ln \mathrm{AOD} \lambda=\ln \beta_{\text {ang }}-\alpha \ln \lambda$.

For calculating the pressure, Eq. (4) is used (Seinfeld and Pandis, 1998):

$p=p_{0} \mathrm{e}^{-h / H}$,

where, $p$ is the site pressure in $\mathrm{hPa}, p_{0}$ is the pressure at sea level in $\mathrm{hPa}, h$ is the altitude of the site in $\mathrm{m}$, and $H$ is the scale height of the atmosphere in $\mathrm{m}$. Scale height is the height at which pressure reduces to $1 / e$ times the sea level pressure. $H$ is calculated by (Seinfeld and Pandis, 1998):

$H=\frac{R_{s} T}{g}$,

where $R_{s}$ is the specific gas constant in $\mathrm{J} \mathrm{kg}^{-1} \mathrm{~K}^{-1}, T$ is the ambient temperature in $\mathrm{K}$ and $g$ is the acceleration due to gravity in $\mathrm{m} \mathrm{s}^{-2} . T$ is obtained from the Weather Underground weather database (TWC, 2020).

\subsection{Transmissivity models}

\subsubsection{Model M1}

A correlation was developed by Tahboub et al. (2013) for modelling the slant path extinction coefficient. This model relates the vertical atmospheric optical depth with the slant path extinction coefficient. The model was validated using ground measured data. The experimental setup was established at the Jabal Hafeet mountain in the United Arab Emirates (UAE). In this experiment, four pyrheliometers were placed at different altitudes between $340 \mathrm{~m}$ and $1035 \mathrm{~m}$ above mean sea level to measure the DNI. The measured data was temperature corrected and calibrated.

Using regression, the relation between the slant path extinction coefficient $\left(\beta_{\text {ext }}\right)$ and the vertical optical depth of the atmosphere $(\tau)$ was obtained. This relation is shown in Eq. (6).

$\beta_{\mathrm{ext}}=0.23 \tau+0.022$

Model M1 takes total vertical optical depth as an input which is derived using REST2 in this work.

\subsubsection{Model M2}

Polo et al. (2016a) presented a sensitivity study on the modelling of the slant path atmospheric attenuation of solar radiation using the libRadTran radiative transfer model. Six AERONET stations (Birdsville, El Arenosillo, Railroad-Valley, Jaipur, Tamanrasset, Solar Village) ranging from clear to hazy atmospheric conditions were considered as an aerosol input. The polynomial fit of the obtained results of the attenuation calculated using the libRadTran was done as a function of the distance $x$ (in $\mathrm{km}$ ) between heliostat and receiver, also known as the slant range:

$T_{r}=1-\left(a_{1} x^{3}+a_{2} x^{2}+a_{3} x+a_{4}\right)$,

where $T_{r}$ is the transmissivity and the coefficients $a_{1}, a_{2}, a_{3}$, and $a_{4}$ are the third order polynomial function of AOD550. As the model by Polo et al. (2016a) is formulated in a polynomial form, it allows for an easy implementation in both ray-tracing and performance assessment tools (Polo et al., 2017). The input for this model i.e. AOD550 is derived from Eq. (1) using AERONET data.

\subsubsection{Model M3}

Hanrieder et al. (2016) improved the model by Sengupta and Wagner (2012) by using more site-specific inputs. In the model by Hanrieder et al. (2016), two additional parameters $a$ and $b$ are derived which depend on the vertical aerosol extinction profile and the precipitable water vapour content in the atmosphere. The slant path extinction coefficient is given as:

$\beta_{\mathrm{ext}}=a\left[-\ln \left(\frac{\mathrm{DNI}}{\mathrm{DNI}_{\text {clean }, \mathrm{sim}}}\right) \cdot \cos \theta\right]+b$,

where $\theta$ is the solar zenith angle, $\mathrm{DNI}_{\text {clean,sim }}$ is calculated DNI for no aerosol condition, $b$ is the offset of the model in $\mathrm{km}^{-1}$ and $a$ is the slope in $\mathrm{km}^{-1}$. The constants $a$ and $b$ are different for different precipitable water vapour concentrations (Hanrieder et al., 2016).

The model by Hanrieder et al. (2016) requires the calculation of coefficients $a$ and $b$ for each site. The same approach, as used by Hanrieder et al. (2016), is also used in this study to calculate $a$ and $b$ using the libRadtran radiative transfer model (Mayer and Kylling, 2005). For the aerosol extinction height profile, the LIVAS global climatology data is used for the three locations (Amiridis et al., 2015). The LIVAS profile for Pune, Kanpur, and Jaipur is shown in Fig. 2. It may be observed from Fig. 2 that Kanpur has the highest aerosol loading in the lower $1 \mathrm{~km}$ region above the ground level among the three sites.

The values of $a$ and $b$ for the three sites for different precipitable water vapour content $(w)$ are given in Table 1 . From Table 1 , it may be observed that $a$ is nearly constant for all the sites, whereas $b$ varies with $w$. As mentioned in Section 2.1.3, the REST2 model is used to 


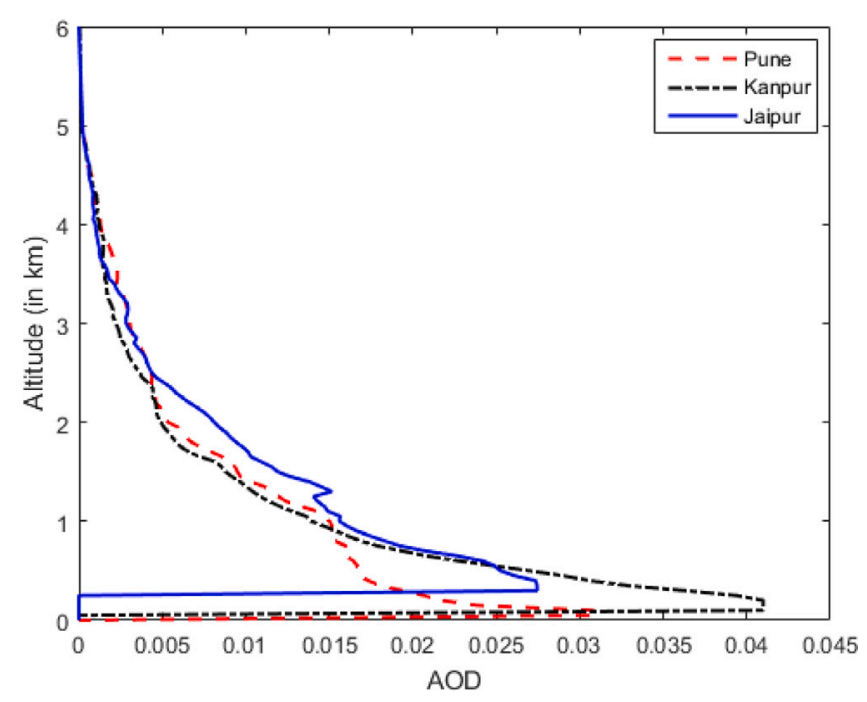

Fig. 2. LIVAS vertical aerosol height profile.

Table 1

Parameters $a$ and $b$ for the three locations Pune, Kanpur, and Jaipur as required by the model M3 (Hanrieder et al., 2016) to calculate the extinction coefficient.

\begin{tabular}{|c|c|c|c|c|c|c|}
\hline \multirow{2}{*}{$\begin{array}{l}w \\
(\mathrm{~mm})\end{array}$} & \multicolumn{2}{|l|}{ Pune } & \multicolumn{2}{|l|}{ Kanpur } & \multicolumn{2}{|l|}{ Jaipur } \\
\hline & $\begin{array}{l}a \\
\left(\mathrm{~km}^{-1}\right)\end{array}$ & $\begin{array}{l}b \\
\left(\mathrm{~km}^{-1}\right)\end{array}$ & $\begin{array}{l}a \\
\left(\mathrm{~km}^{-1}\right)\end{array}$ & $\begin{array}{l}b \\
\left(\mathrm{~km}^{-1}\right)\end{array}$ & $\begin{array}{l}a \\
\left(\mathrm{~km}^{-1}\right)\end{array}$ & $\begin{array}{l}b \\
\left(\mathrm{~km}^{-1}\right)\end{array}$ \\
\hline 0 & 0.674195 & 0.008564 & 1.010814 & 0.008809 & 0.780956 & 0.008626 \\
\hline 10 & 0.674204 & 0.025562 & 1.010822 & 0.025351 & 0.780963 & 0.025419 \\
\hline 20 & 0.674206 & 0.029507 & 1.010823 & 0.029167 & 0.780966 & 0.029308 \\
\hline 30 & 0.674208 & 0.032289 & 1.010825 & 0.031827 & 0.780967 & 0.032040 \\
\hline
\end{tabular}

calculate DNI and $\mathrm{DNI}_{\text {clean,sim }}$ for 'with aerosol' and 'without aerosol' conditions, respectively. For the comparison of transmissivity values calculated from the model M3 with respect to the other two models, all the inputs of REST2 model are taken from the AERONET station. $\alpha$ and $\beta_{\text {ang }}$ are derived using Eq. (3).

Model M3 is used to calculate the transmissivity using satellite data. The transmissivity values calculated using satellite data is then compared with the transmissivity values calculated using AERONET data to assess the feasibility of using satellite data in place of ground-based data. However, in the comparison of transmissivity values calculated using MODIS data with respect to transmissivity values calculated using AERONET data, Ångstrom exponent $\alpha$ and Ångstrom turbidity coefficient $\beta_{\text {ang }}$ are not directly available in MODIS data. From collection 6 , Ångstrom exponent for land is not being reported. The relation given by Eq. (9) is used for calculating $\alpha$ using MODIS AOD data (Zhong and Kleissl, 2015).

$\alpha=-\frac{\ln \frac{\mathrm{AOD} \lambda_{2}}{\operatorname{AOD} \lambda_{1}}}{\ln \frac{\lambda_{2}}{\lambda_{1}}}$

Three possible combinations of the available AOD and the corresponding wavelength are used to estimate the value of $\alpha$. In order to obtain a single value of $\alpha$ for the solar spectrum wavelength range, the average of the three $\alpha$ values at $470 \mathrm{~nm}, 550 \mathrm{~nm}$, and $660 \mathrm{~nm}$ is used in this study. For calculating $\beta_{\text {ang }}$, AOD550 is considered as (Zhong and Kleissl, 2015):

$\beta_{\text {ang }}=\operatorname{AOD550} \lambda^{\alpha}$.

The other inputs for the REST2 model (water vapour amount, ozone amount, nitrogen dioxide amount) are taken from the AERONET data. Water vapour amount can also be calculated using an empirical relation given by Gueymard (1993).

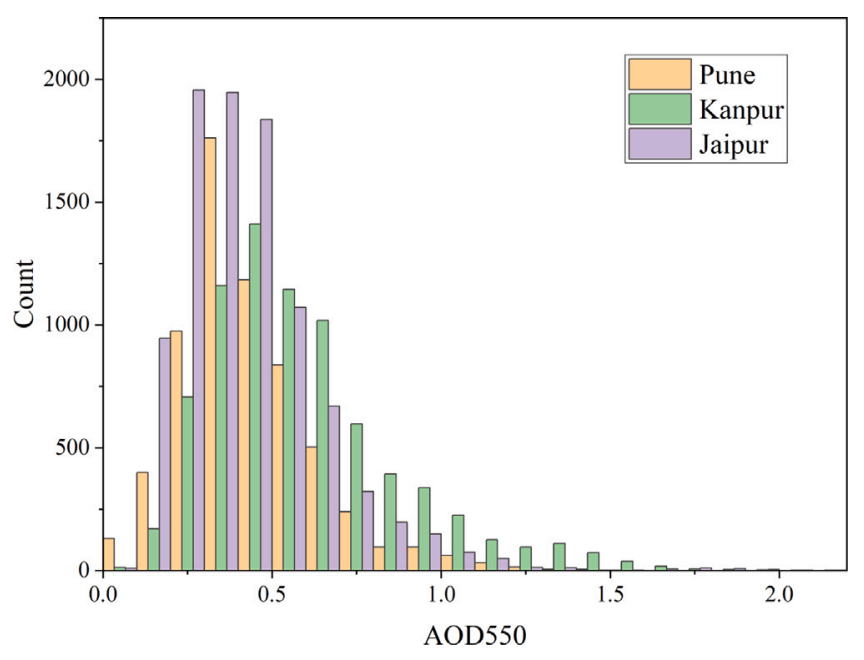

Fig. 3. Frequency distribution histogram plot of AERONET AOD550 for Pune, Kanpur, and Jaipur.

\subsection{Statistical parameters for comparative analysis}

The statistical parameters used for the comparative analysis are given by:

Mean bias error $(\mathrm{MBE})=\frac{1}{N} \sum_{N}\left(T_{\mathrm{M} 3}-T_{\mathrm{q}}\right)$

Mean relative error $(\mathrm{MRE})=\frac{1}{N} \sum_{N} \frac{\left(\left|T_{\mathrm{M} 3}-T_{\mathrm{q}}\right|\right)}{T_{\mathrm{M} 3}}$

$\mathrm{R}^{2}=1-\frac{\sum_{N}(\text { AERONET AOD550 - MODIS AOD550 })^{2}}{\sum_{N}\left(\text { AERONET AOD550 - }\langle\text { AERONET AOD550 })^{2}\right.}$

where $T$ is the transmissivity. The subscript of $T$ denotes the models that are used to calculate the transmissivity. Here $q$ stands for M1, $\mathrm{M} 2$, and M3,sat. M3,sat is model M3 with satellite data. $N$ is the total number of data points.

\section{Results and discussion}

\subsection{Analysis of AOD levels and sources}

\subsubsection{AOD550 levels at each location}

The AERONET AOD550 for Pune, Kanpur, and Jaipur is compared in Fig. 3 using data from 2015 and a frequency distribution histogram plot. For this comparison, 6340, 7656, and 9282 data points are selected for Pune, Kanpur, and Jaipur, respectively. Kanpur is relatively higher aerosol loaded than Pune and Jaipur (Fig. 3). Kanpur is an urban-industrial city in the Ganga basin. With the increase in industrialization and urbanization, the pollution and aerosol loading also increased in Kanpur (Singh et al., 2004). It may be observed from Fig. 3 that the number of counts for AOD550 greater than 1 is significantly less for Pune and Jaipur compared to Kanpur. For Pune and Jaipur, most of the frequency distribution peaks occur between 0.2 and 0.7 . For Jaipur, maximum number of AOD550 data points lie between 0.25 to 0.5 . The maximum number of count for Pune lies near the AOD550 value of 0.25 . While for Kanpur, it is well distributed over the range of 0.25 to 1 . The mean AOD550 value for Pune, Kanpur, and Jaipur is $0.43,0.59$, and 0.42 , respectively.

\subsubsection{Comparison of AOD550 from AERONET and MODIS}

The comparison of AERONET and MODIS data for AOD550 for Pune, Kanpur, and Jaipur is shown in Fig. 4. The coefficient of determination $\mathrm{R}^{2}$ for Pune, Kanpur, and Jaipur is $0.74,0.77$, and 0.64 , respectively. $R^{2}$ tells the extent to which any variable can be predicted by some independent variable. Although Kanpur is highly aerosol 


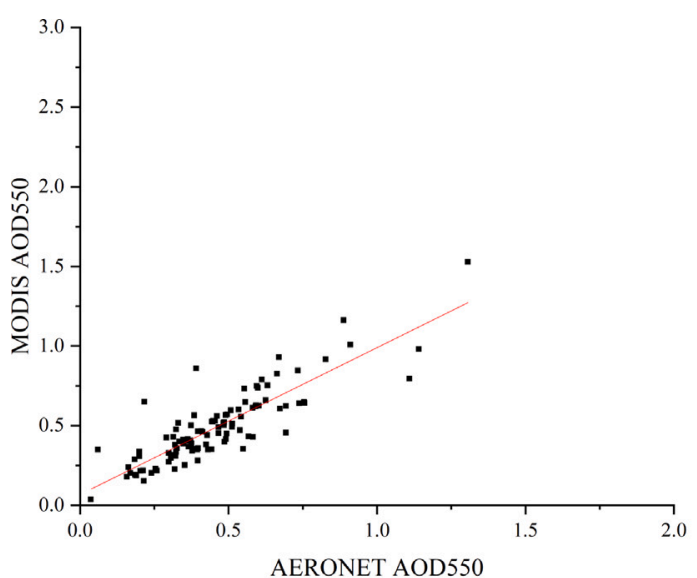

(a) Pune

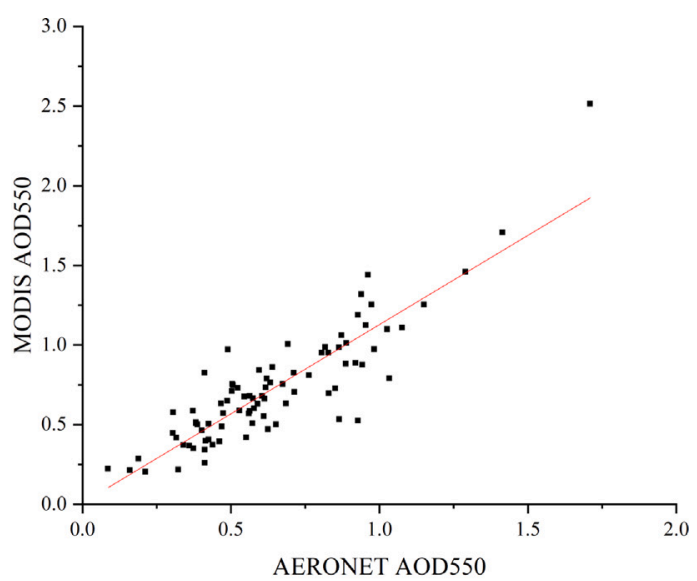

(b) Kanpur

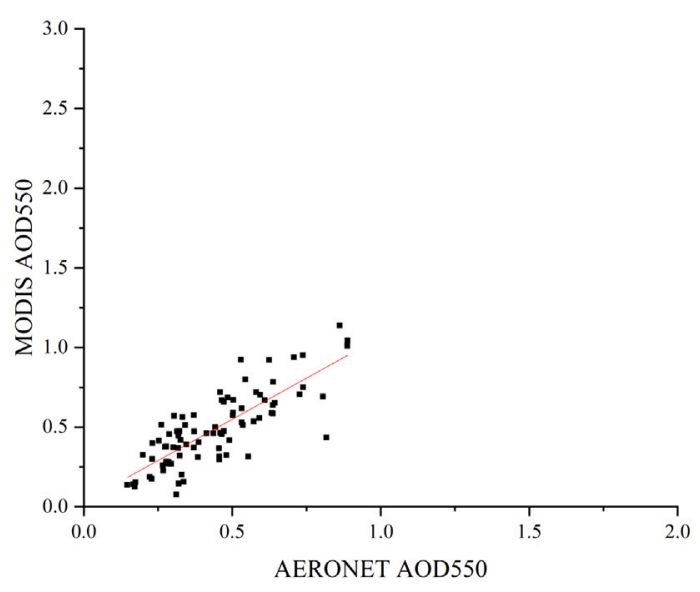

(c) Jaipur

Fig. 4. Comparison of AERONET and MODIS AOD550 values.

loaded, it also has the highest $\mathrm{R}^{2}(0.77)$ which means that $77 \%$ of the total variation in MODIS AOD can be explained by the linear relationship between AERONET AOD and MODIS AOD.

\subsection{Comparison of transmissivity using AERONET AOD data}

The comparison of the transmissivity values estimated using the three models for Pune, Kanpur, and Jaipur is shown in Fig. 5. For this comparison, a total of 6340,7656 , and 9282 data points are taken from AERONET data set of year 2015 for Pune, Kanpur, and Jaipur, respectively. From Fig. 5, it may be observed that the three models predict similar results for some range of inputs, while at other times, model M1 and M2 differ from model M3 significantly. These similarities and differences are mainly because of the dependency of the models on AOD, as each model takes aerosol concentration as an input in different ways. This dependency is highlighted in Fig. 6, which shows the transmissivity estimated using the three models with AOD550 for Pune, Kanpur, and Jaipur. For AOD550 less than 0.3, the relative error in the transmissivity values estimated by the models M1 and M2 with respect to model M3 is less than $10 \%$ for Pune, $18 \%$ for Kanpur, and $12 \%$ for Jaipur. Models M1 and M2 calculate similar transmissivity values for AOD550 less than 0.4. However, as AOD550 increases, the difference between the transmissivity values estimated by models M1 and M2 with respect to model M3 also increases.
The results from the model M2 differ more rapidly with respect to model M3 as the model was developed for AOD550 values up to 0.80 , beyond which the model may result in extremely high attenuation as it is a third order polynomial of AOD550. The model M1 results in higher transmissivity values for all the data points for all the sites (transmissivity values for the three regions range from 0.80 to 0.95 ). The model M2 shows a large drop in the transmissivity values for AOD550 greater than 1. For Pune, models M1 and M2 do not differ much from model M3 for AOD550 less than 0.8. For Kanpur, for some data points where AOD550 is less than about 0.45, models M1 and M2 estimate similar results whereas the model M3 gives lower values. Similarly, for some data points where AOD550 ranges between 0.7 and 1.1, models M2 and M3 estimate similar values while the model M1 gives higher values. Models M1 and M2 also have significant differences from model M3 for those data points (Fig. 6(b)) where AOD550 is greater than 1.2. For Jaipur (Fig. 6(c)), all the models calculate similar transmissivity values for AOD550 less than 0.4. The difference in transmissivity values calculated by model M2 and model M3 is significantly low for AOD550 less than 0.9. For AOD550 greater than 1.0, models M1 and M2 have significant differences from model M3 for Jaipur. It may be observed that even for large values of AOD550, the transmissivity values obtained from model M1 do not decrease much. For example, for AOD550 equal to 1.7 , the transmissivity values estimated by models M2 and M3 are -0.23 and 0.36 , respectively, 


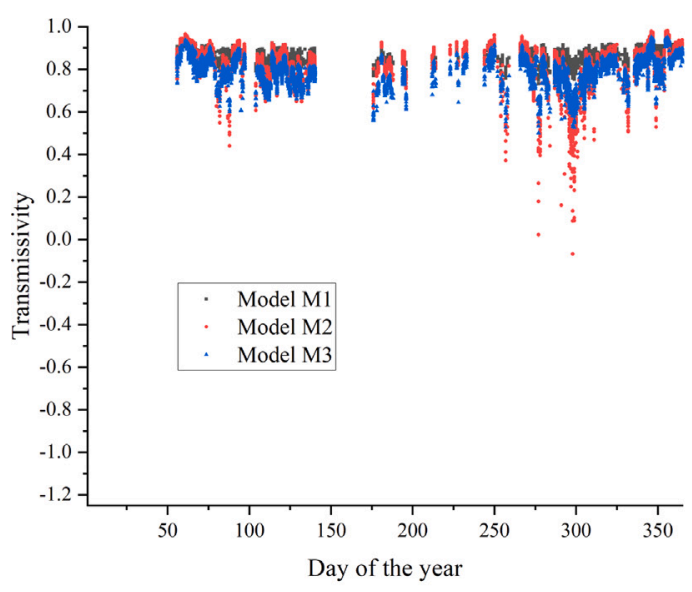

(a) Pune

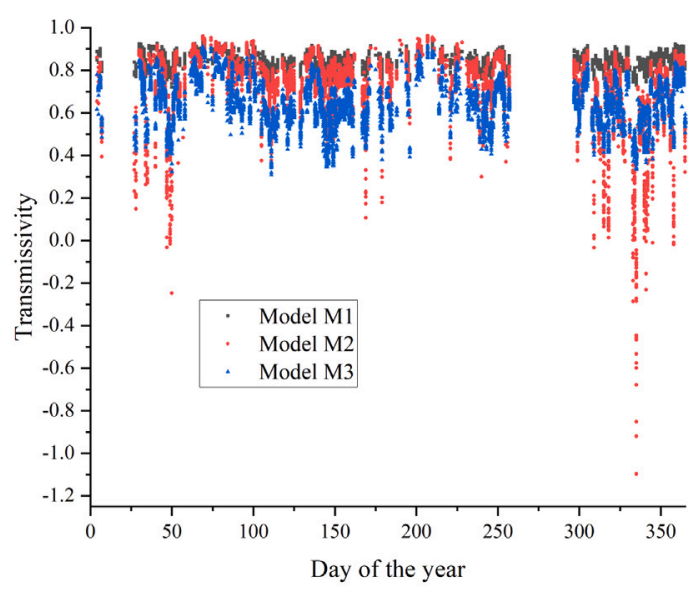

(b) Kanpur

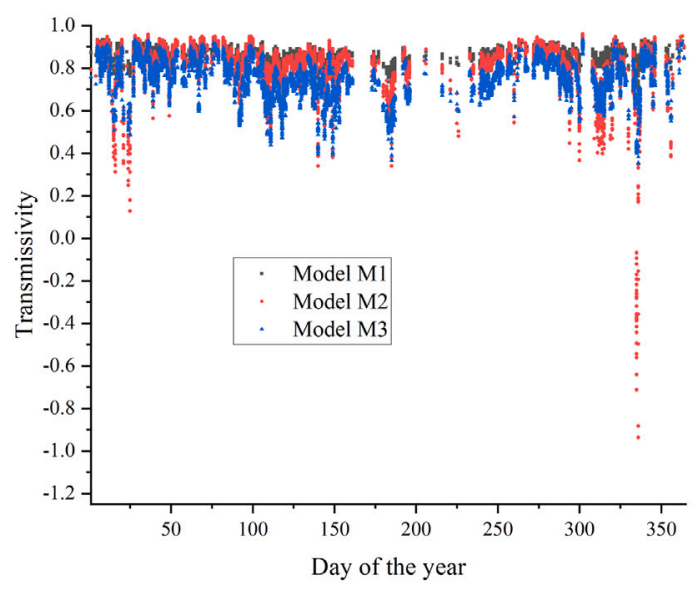

(c) Jaipur

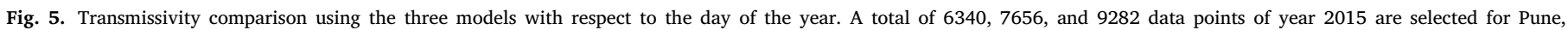
Kanpur, and Jaipur, respectively.

whereas model M1 gives a transmissivity of 0.74. For low AOD550 (less than 0.6 ), the model M2 estimates higher values of transmissivity than those obtained from the model M3 (maximum difference about 0.1). After a certain value of AOD550 (for Pune around 0.7, for Kanpur around 0.9, and for Jaipur around 0.85), the model M2 estimates lower transmissivity values than the model M3. From Figs. 6(b) and 6(c), it may be observed that the model M2 results negative transmissivity values for high AOD550 values (greater than 1.6). It may be concluded from this that the model M2 has a certain limit of AOD550, after which it may not be reliable for the estimation of transmissivity. The mean error analysis of model comparison for transmissivity values is given in Table 2. The MBE for the three sites is negative for both the models M1 and M2 in comparison to model M3 which indicates that over the chosen period of time, models M1 and M2 estimate transmissivity higher than the model M3. The MRE of model M2 is the highest for Kanpur. It is because for Kanpur, the number of count for AOD550 values greater than 1.6 is the highest and model M2 estimates negative transmissivity for AOD550 greater than 1.6.

The outputs from the models M2 and M3 decrease rapidly with respect to the increase of aerosol optical depth, whereas the output from the model M1 is not highly sensitive to aerosol optical depth. From the results of the three sites, it may be noted that there is a threshold value of AOD550 below which the model M2 estimates the
Table 2

Mean error analysis of attenuation models.

\begin{tabular}{lllll}
\hline Sites & $\begin{array}{l}\text { MBE } \\
\text { (M3-M1) }\end{array}$ & $\begin{array}{l}\text { MBE } \\
\text { (M3-M2) }\end{array}$ & $\begin{array}{l}\text { MRE (\%) } \\
\text { (M3-M1) }\end{array}$ & $\begin{array}{l}\text { MRE (\%) } \\
\text { (M3-M2) }\end{array}$ \\
\hline Pune & -0.077 & -0.029 & 10.24 & 5.96 \\
Kanpur & -0.196 & -0.085 & 33.07 & 19.99 \\
Jaipur & -0.106 & -0.059 & 15.14 & 9.98 \\
\hline
\end{tabular}

transmissivity higher than model M3. The model M2 however has a limitation. For Kanpur and Jaipur, it resulted in negative transmissivity values for AOD550 greater than 1.6. This limitation is because the maximum AOD550 considered in deriving the model M2 was 0.72 . The model M2 therefore could be used for AOD550 values less than 0.72 . Within the range of applicability, the model M2 works in high agreement with the model M3.

\subsection{Sensitivity study of model M3 to AOD variations}

In this study, AERONET and MODIS Terra satellite data for the year 2015 is considered. The months of March, April, May, October, November, and December were selected for this study as AERONET provides uniformly distributed data for these months. The data for the other months is affected by the rainy and the winter seasons. Since Terra passes equator at +5 UTC, the AERONET data used in this study is 


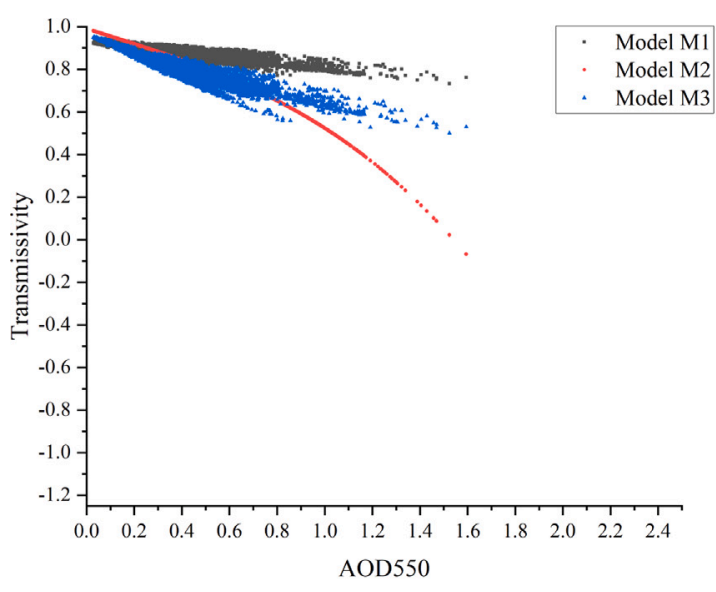

(a) Pune

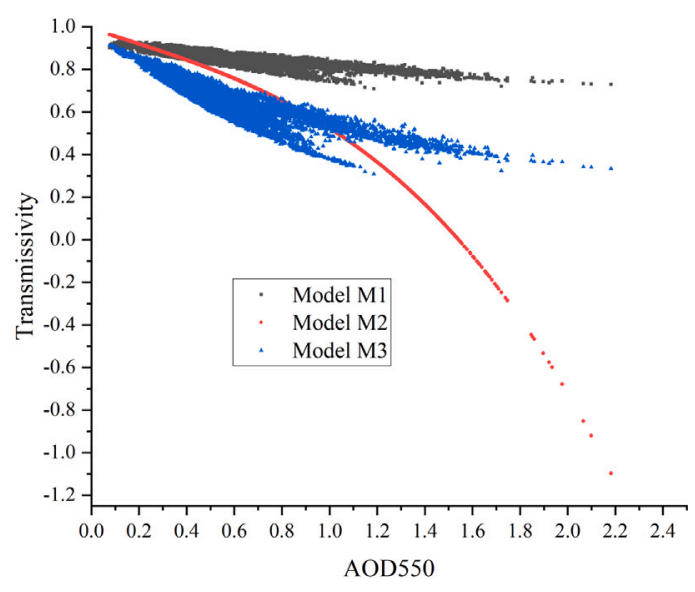

(b) Kanpur

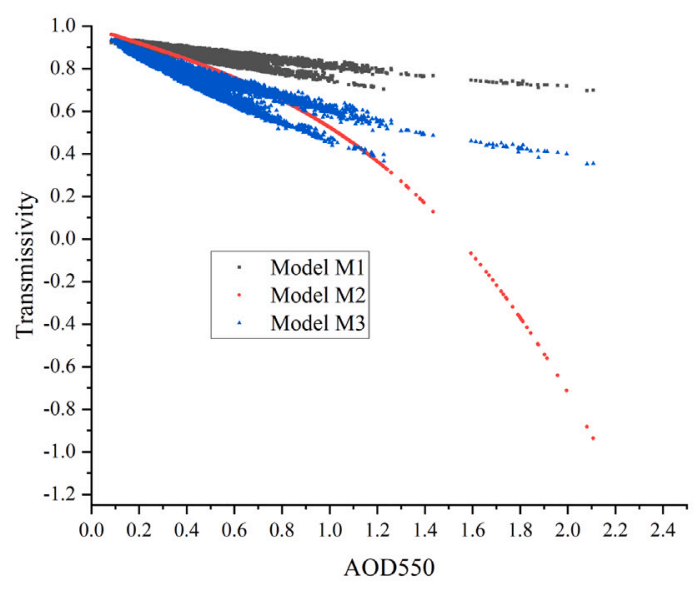

(c) Jaipur

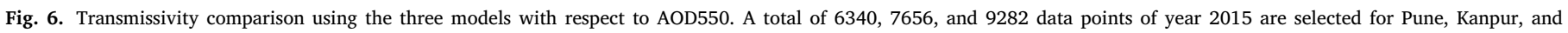
Jaipur, respectively.

also taken at the same time with a time window of $\pm 30 \mathrm{~min}$. The data set used in this study are taken from the intersection of the database of AERONET and MODIS for the selected months. For Pune, Kanpur, and Jaipur, total 105, 85, and 84 data points of the year 2015 are used, respectively.

The comparison of the obtained transmissivity values using the AERONET and the MODIS data for Pune, Kanpur, and Jaipur with the model M3 is shown in Fig. 7. For Pune, the MBE is small (0.002). For Kanpur and Jaipur, except for some points, the deviation in transmissivity values using MODIS data with respect to using AERONET data is not significantly high. The MRE is $10.2 \%$ for Kanpur and $9.2 \%$ for Jaipur. Another comparison of difference in transmissivity values calculated using MODIS data and AERONET data, with respect to difference in MODIS AOD550 and AERONET AOD550 for Pune, Kanpur, and Jaipur is shown in Fig. 8. The maximum difference in transmissivity values obtained using the MODIS data with respect to using the AERONET data for Pune, Kanpur, and Jaipur are $19.6 \%$, $79.6 \%$, and $47.6 \%$, respectively. The corresponding differences in the AOD550 values are $119.4 \%, 43.3 \%$, and $46.9 \%$. However, the average values of MRE given in Table 3 are not significantly large for the three sites. For Kanpur and Jaipur (Figs. 8(b) and 8(c)), most of the data have less than 0.1 difference in transmissivity values calculated using MODIS data and using AERONET data. It may be observed from Fig. 8 that the difference
Table 3

Mean error analysis with model M3 using AERONET and MODIS data.

\begin{tabular}{lll}
\hline Sites & $\mathrm{MBE}_{\text {sat }}$ & $\mathrm{MRE}_{\text {sat }}(\%)$ \\
\hline Pune & 0.002 & 4.8 \\
Kanpur & 0.011 & 10.2 \\
Jaipur & -0.017 & 9.2 \\
\hline
\end{tabular}

of 0.2 in AERONET AOD550 and MODIS AOD550 resulted in only about 0.05 to 0.08 difference in transmissivity values using AERONET AOD and MODIS AOD data. Regression analysis between the difference in transmissivity values calculated using MODIS data with respect to using AERONET data and difference in AERONET AOD550 and MODIS AOD550 is also done and the results can be seen in Fig. 8. The slope of these regressions for Pune, Kanpur, and Jaipur are $0.286,0.22$, and 0.278 respectively. The differences in the slopes are not significantly high but it is mainly due to the different vertical aerosol profiles used by model M3 for the three sites.

The results indicate that for low aerosol concentration, i.e. AOD550 less than 0.3-0.4, the MRE is not higher than $5 \%$ (10\% for Kanpur), and as the concentration increases, the difference between the transmissivity values using AERONET data and using MODIS data also increases. 


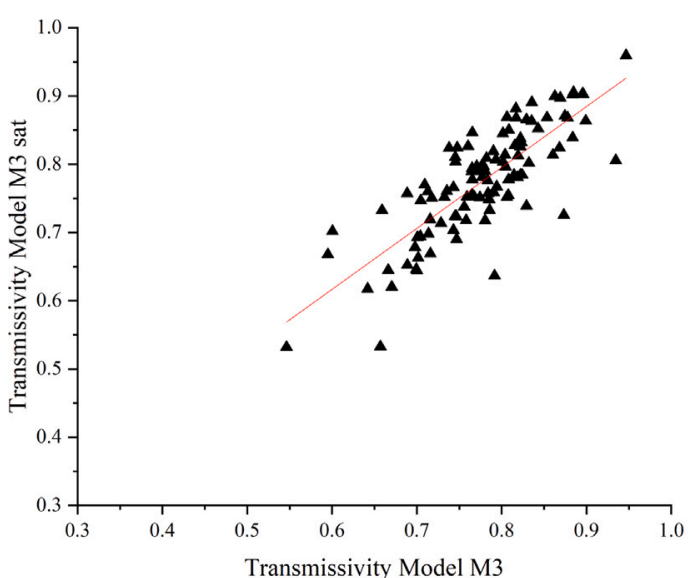

(a) Pune

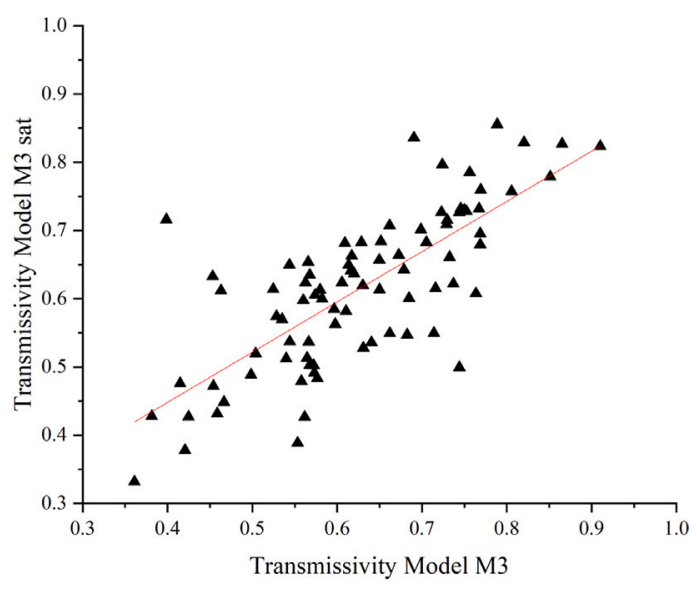

(b) Kanpur

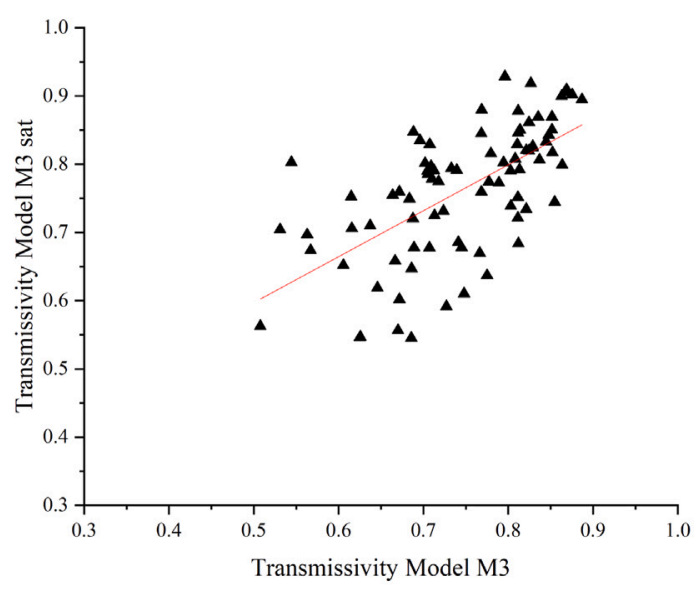

(c) Jaipur

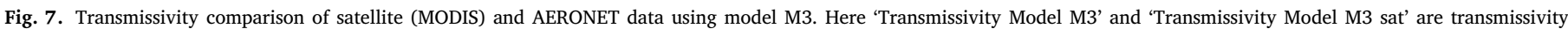

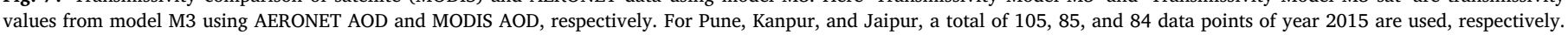

The comparative analysis of satellite (MODIS) AOD550 with AERONET AOD550 presents an alternative towards using satellite data for slant path atmospheric attenuation calculation in central receiver solar thermal plants. The results indicate that the transmissivity values estimated using the satellite data for low and moderate aerosol concentrated areas (Pune and Jaipur) is better than that for the highly aerosol concentrated areas (Kanpur). This is because the satellite AOD product for $550 \mathrm{~nm}$ shows a relatively good match with the ground measurement for Pune and Jaipur. For Kanpur, the deviation is also not significantly high, except for some higher AOD550 values. Kanpur shows a relatively constant difference between satellite (MODIS) AOD and the ground (AERONET) AOD values, and therefore also in the transmissivity values.

\section{Conclusion}

This study aimed at assessing the sensitivity of the attenuation models for different atmospheric conditions. The study also aimed at evaluating the feasibility of using satellite data to estimate the slant path attenuation in the lower atmosphere. Three attenuation models, Tahboub et al. (2013) - model M1, Polo et al. (2016a) - model M2, and Hanrieder et al. (2016) - model M3, were considered and assessed. Three AERONET sites (Pune, Kanpur, and Jaipur) were considered.
For comparison of attenuation models, year 2015 is considered. The AOD550 comparison for the three sites shows that Pune and Jaipur have relatively lower AOD550 (most data points lie in the range of 0.2-0.7) than that of Kanpur (range 0.25-1). Satellite (MODIS) AOD550 and AERONET AOD550 values were compared for the three sites. The comparison of AOD550 from AERONET and MODIS showed $\mathrm{R}^{2}$ value of Kanpur (0.77) higher than that of Pune (0.74) and Jaipur (0.64).

The comparison of the attenuation models suggest a large difference in the output of the models for high aerosol concentrations. The model M1 is not highly sensitive to the aerosol concentration in the atmosphere whereas the model M2 differs significantly from model M3 for AOD550>1. In the second comparison, satellite data was used to estimate the transmissivity values for the three sites using the model M3. Then, the transmissivity values obtained using the AERONET data and the satellite (MODIS) data are compared for the three sites. The mean relative errors in the transmissivity values calculated using MODIS data with respect to using AERONET data for Pune, Kanpur, and Jaipur are $4.8 \%, 10.2 \%$, and $9.2 \%$ respectively. Interestingly, the MBE (in the transmissivity values using MODIS AOD from using AERONET AOD) for Pune is very low (0.002), but Jaipur (-0.017) has a higher value than Kanpur (0.011) which means that for Jaipur, model M3 calculates higher transmissivity using MODIS AOD data compared to using AERONET AOD data. Thus, for Jaipur, for most of the data points MODIS AOD has lower value compared to the AERONET AOD. 


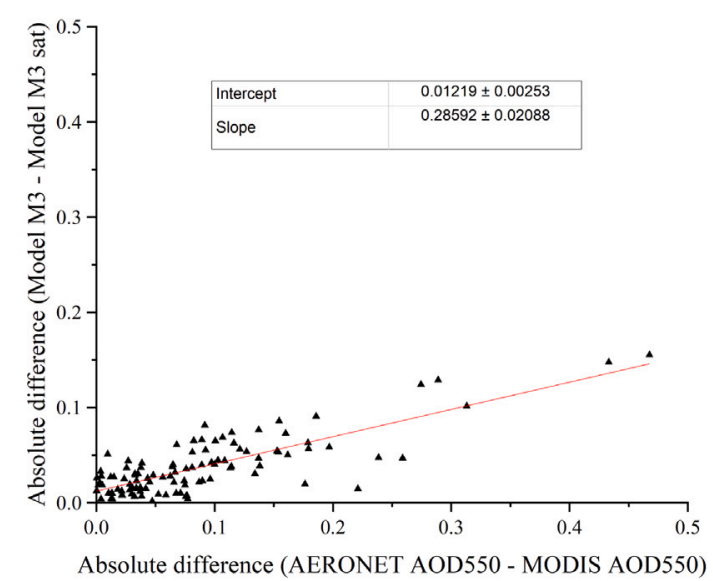

(a) Pune

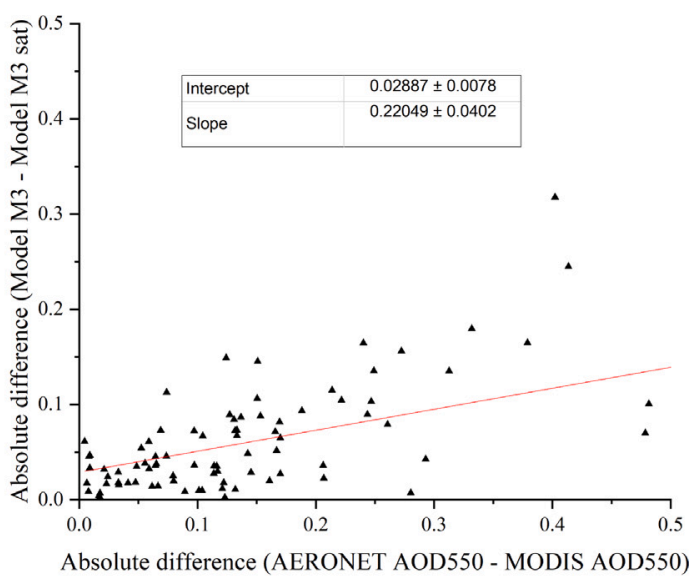

(b) Kanpur

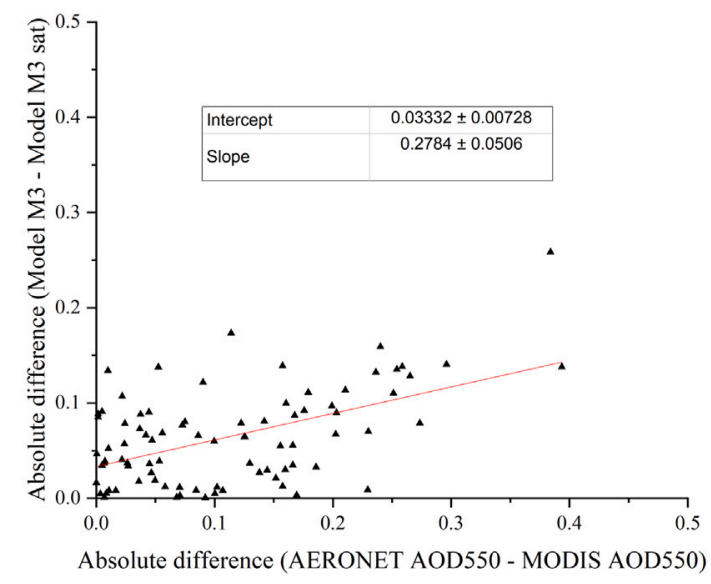

(c) Jaipur

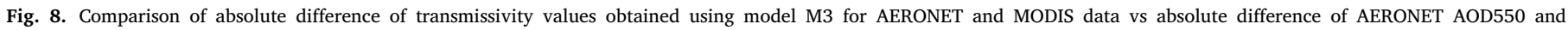
MODIS AOD550.

In conclusion, models $\mathrm{M} 1$ and $\mathrm{M} 2$ give similar results compared to model M3 within $5 \%$ MRE for AOD550 values less than 0.3. As the AOD550 value increases, the results from the models M1 and M2 have large differences from model M3. For highly aerosol concentrated areas, the suitability of these models is still a question. There is a need for experimental validation of these models for sites with varied aerosol concentration and composition. The study also suggests that satellite AOD can be an alternative for calculating slant path atmospheric attenuation in the lower atmosphere. However, a prior correction of the satellite AOD data is recommended for high aerosol loaded areas.

\section{Declaration of competing interest}

The authors declare that they have no known competing financial interests or personal relationships that could have appeared to influence the work reported in this paper.

\section{Acknowledgements}

The authors gratefully acknowledge the principle investigator and his team of AERONET at Pune, Kanpur, and Jaipur sites for providing good quality data. We also thank the MODIS team for generating the AOD data.

\section{References}

Ahlbrink, N., Belhomme, B., Flesch, R., M. Quinto, D., Rong, A., Schwarzbözl, P., 2012. STRAL: Fast ray tracing software with tool coupling capabilities for high-precision simulations of solar thermal power plants. In: Proceedings of the SolarPACES 2012 Conference Marrakech, Morocco.

Amiridis, V., Marinou, E., Tsekeri, A., Wandinger, U., Schwarz, A., Giannakaki, E., Mamouri, R., Kokkalis, P., Binietoglou, I., Solomos, S., Herekakis, T., Kazadzis, S., Gerasoloulos, E., Balis, D., Papayannis, A., Kontoes, C., Kourtidis, K., Papagiannopoulos, N., Mona, L., Pappalardo, G., Le Rille, O., Ansmann, A., 2015. LIVAS: a 3-D multi wavelength aerosol/cloud climatology based on CALIPSO and EARLINET. Atmos. Chem. Phys. Discuss. 15, 2247-2304.

Ballestrìn, J., Marzo, A., 2012. Solar radiation attenuation in solar tower plants. Sol. Energy 86, 388-392.

Belhomme, B., Pitz-Paal, R., Schwarzbözl, P., Ulmer, S., 2009. A new fast ray tracing tool for high-precision simulation of heliostat fields. J. Solar Energy Eng. 131.

Buck, R., 2011. Solar power ray tracing tool SPRAY. Manual Version 5.20.

Carra, E., Marzo, A., Ballestrín, J., Polo, J., Barbero, J., Alonso-Montesinos, J., Monterreal, R., Abreu, E., Fernández-Reche, J., 2020. Atmospheric extinction levels of solar radiation using aerosol optical thickness satellite data. Validation methodology with measurement system. Renew. Energy 149, 1120-1132.

Chakraborty, A., Gupta, T., 2009. Chemical characterization of submicron aerosol in Kanpur region: a source apportionment study. Int. J. Environ. Ecol. Eng. 3 (3).

Elias, T., Ramon, D., Dubus, L., Bourdil, C., Cuevas-Agulló, E., Zaidouni, T., Formenti, P., 2016. Aerosols attenuating the solar radiation collected by solar tower plants: The horizontal pathway at surface level. AIP Conf. Proc. 1734, 150004.

Elias, T., Ramon, D., Garnero, M.A., Dubus, L., Bourdil, C., 2017. Solar energy incident at the receiver of a solar tower plant, derived from remote sensing: Computation of both DNI and slant path transmittance. AIP Conf. Proc. 1850, 140005. 
Gadgil, A., Dhorde, A., 2005. Temperature trends in twentieth century at Pune, India. Atmos. Environ. 39, 6550-6556.

Geiger, R., 1954. Klassifikation der klimate nach W. Köppen (Classification of Climates after W. Köppen) In: Landolt-Börnstein - Zahlenwerte und Funktionen aus Physik, Chemie, Astronomie, Geophysik und Technik, alte Serie, vol. 3, Springer, Berlin, pp. 603-607.

Gueymard, C., 1993. Assessment of the accuracy and computing speed of simplified saturation vapor equations using a new reference data set. J. Appl. Meteorol. 32, 1294-1300.

Gueymard, C., 2008. REST2: High-performance solar radiation model for cloudless-sky irradiance, illuminance, and photosynthetically active radiation - validation with a benchmark data set. Sol. Energy 82, 272-285.

Gueymard, C., López, G., Rapp-Arrarás, I., 2017. Atmospheric transmission loss in mirror-to-tower slant ranges due to water vapor. AIP Conf. Proc. 1850, 140010.

Gueymard, C., Yang, D., 2020. Worldwide validation of CAMS and MERRA-2 reanalysis aerosol optical depth products using 15 years of AERONET observations. Atmos. Environ. 225, 117216.

Hanrieder, N., 2016. Determination of Atmospheric Extinction for Solar Tower Plants (Ph.D. thesis). RWTH Aachen, DLR.

Hanrieder, N., Ghennioui, A., Merrouni, A.A., Wilbert, S., Wiesinger, F., Sengupta, M., Zarzalejo, L., Schade, A., 2019. Atmospheric transmittance model validation for CSP tower plants. Remote Sens. 11, 1083.

Hanrieder, N., Sengupta, M., Xie, Y., Wilbert, S., Pitz-Paal, R., 2016. Modeling beam attenuation in solar tower plants using common DNI measurements. Sol. Energy 129, 244-255.

Hanrieder, N., Wilbert, S., Mancera-Guevara, D., Buck, R., Giuliano, S., Pitz-Paal, R., 2017. Atmospheric extinction in solar tower plant, A review. Sol. Energy 152, 193-207.

Holben, B., Eck, T., Slutsker, I., Tanre, D., Buis, J., Setzer, A., Vermote, E., Reagan, J., Kaufman, Y., Nakajima, T., Lavenu, F., Jankowiak, I., Smirnov, A., 1998. AERONET: a federated instrument network and data archive for aerosol characterization. Remote Sens. Environ. 66, 1-16.

Iqbal, M., 1983. An Introduction to Solar Radiation. Academic Press.

Kistler, B.L., 1986. A user's manual for DELSOL3: A computer code for calculating the optical performance and optimal system design for solar thermal central receiver plants. Manual.

Leary, P., Hankins, J., 1979. A user's guide for MIRVAL - A computer code for comparing design of heliostat-receiver optics for central receiver solar power plants. Manual.

López, G., Gueymard, C.A., Bosch, J.L., 2017. Evaluation of solar energy losses for the heliostat-to-receiver path of a tower solar plant for different aerosol models. In: ISES Solar World Congress.

Mayer, B., Kylling, A., 2005. Technical note: The libRadtran software package for radiative transfer calculations - description and examples of use. Atmos. Chem. Phys. 5, 1855-1877.

Pitman, C., Vant-Hull, L., 1982. Atmospheric transmission model for a solar beam propagating between a heliostat and a receiver. ASES Prog. Solar Energy 1247-1251.

Polo, J., Antonanzas-Torres, F., Vindel, J.M., Ramirez, L., 2014. Sensitivity of satellitebased methods for deriving solar radiation to different choice of aerosol input and models. Renew. Energy 68, 785-792.
Polo, J., Ballestrìn, J., Alonso-Montesinos, J., López-Rodriguez, G., Barbero, J., Carra, E. Fernández-Reche, J., Bosch, J.L., Batlles, F.J., 2017. Analysis of solar tower plant performance influenced by atmospheric attenuation at different temporal resolutions related to aerosol optical depth. Sol. Energy 157, 803-810.

Polo, J., Ballestrín, J., Carra, E., 2016a. Sensitivity study for modelling atmospheric attenuation of solar radiation with radiative transfer models and the impact in solar tower plant production. Sol. Energy 134, 219-227.

Polo, J., Wilbert, S., Ruiz-Arias, J.A., Meyer, R., Gueymard, C., Suri, M., Martin, L., Mieslinger, T., Blanc, P., Grant, I., Boland, J., Ineichen, P., Remund, J., Escobar, R., Troccoli, A., Sengupta, M., Nielsen, K.P., Renne, D., Geuder, N., Cebecaue, T., 2016b. Preliminary survey on site-adaptation techniques for satellite-derived and reanalysis solar radiation data sets. Sol. Energy 132, 25-37.

Remer, L.A., Kaufman, Y.J., Tanré, D., Mattoo, S., Chu, D.A., Martins, J.V., Li, R., Ichoku, C., Levy, R.C., Kleidman, R.G., Eck, T.F., Vermote, E., Holben, B.N., 2005. The MODIS aerosol algorithm, products, and validation. J. Atmos. Sci. 62, 947-973.

Schwarzbözl, P., Schmitz, M., Pitz-Paal, R., 2009. Visual HFLCAL - a software tool for layout and optimization of heliostat fields. In: Proceedings of the SolarPACES 2009 Conference Berlin, Germany.

Seinfeld, J.H., Pandis, S.N., 1998. Atmospheric Chemistry and Physics from Air Pollution to Climate Change. John Wiley, New York.

Sengupta, M., Wagner, M., 2012. Atmospheric attenuation in central receiver systems from DNI measurements. In: Proceedings of the SolarPACES 2012 Conference Marrakech, Morocco.

Singh, R., 2018. Indian Institute of Remote Sensing, Indian Space Research Organisation (ISRO) (personal communication).

Singh, R.P., Dey, S., Tripathi, S.N., Tare, V., Holben, B., 2004. Variability of aerosol parameters over Kanpur, northern India. J. Geophys. Res. 109, D23206.

Singh, R., Singh, C., Ojha, S.P., Kumar, A.S., Kumar, A.S.K., 2017. Development of an improved aerosol product over the Indian subcontinent: Blending model, satellite, and ground-based estimates. J. Geophys. Res. 122 (1), 367-390.

Tahboub, Z., Oumbe, A., Hassar, Z., Obaidli, A., 2013. Modeling of irradiance attenuation from a heliostat to the receiver of a solar central tower. Energy Procedia 49, 2405-2413.

TWC, 2020. Weather underground weather database. URL: https://www.wunderground. com/. (Last Accessed 23 August 2020).

Tyagi, A., Singh, O., Singh, S., Kumar, S., 2011. Climate of Jaipur. Meteorological Centre, Jaipur India Meteorological Department Ministry of Earth Sciences Government of India.

Vittitoe, C., Biggs, F., 1978. Terrestrial propagation loss. In: American Section of ISES Meeting. Denver, August 1978, Sandia release.

Vittitoe, C., Biggs, F., 1981. A User's Guide to Helios: A Computer Program for Modeling the Optical Behavior of Reflecting Solar Concentrators. Tech. Rep. Sandia.

Wei, J., Li, Z., Peng, Y., Sun, L., 2019. MODIS Collection 6.1 aerosol optical depth products over land and ocean: validation and comparison. Atmos. Environ. 201, $428-440$.

Zhong, X., Kleissl, J., 2015. Clear sky irradiances using REST2 and MODIS. Sol. Energy $116,144-164$ 